\title{
Lightning Effect on Copper and Optical Fiber (FTTN) Access Networks of Telecommunication Systems
}

\author{
B.T. Hemamali, D.G.A.R. Lakmali, H.M.T.M. Kumari, M.A.R.M. Fernando and \\ J.R.S.S. Kumara
}

\begin{abstract}
This paper presents a study of lightning effect on copper and optical fiber (fiber to the node) public switched telephone network (PSTN) in Sri Lanka. The study covers, firstly modeling and simulation of each PSTNs, secondly development and testing of PSTN laboratory prototypes and finally a case study for a selected real network. The individual PSTNs were modeled by PSCAD/EMTDC software and were verified in the laboratory by applying lightning surges to the developed prototypes. The study was extended by considering the effects of typical earth resistances in the PSTN and possible multiple reflections. In the case study, first the RLC parameters of the PSTN were estimated by field and laboratory measurements. Then, the PSTN was modeled and analyzed in PSCAD/EMTDC software. It was found that significant components of lightning surges may transfer to the consumer side unless proper surge protective devices are used. Further, this effect may be higher in the optical fiber network compared to the copper network. A significant effect may also appear at the subscriber side due to multiple reflections and the earth resistances characterized by high soil resistivity.
\end{abstract}

Keywords: Lightning surge, telecommunication system, PSCAD/EMTDC, PSTN, soil resistivity, multiple reflections

\section{Introduction}

Lightning is an electrostatic discharge occurring between electrically charged regions within clouds or between a cloud and the ground. As a result, lightning surges may propagate through service wires to the customer [1]. Thus the surges cause failures and damages to almost every electrical and electronic system that are exposed to thunderstorms directly or indirectly. The problem may become severe especially for telecommunication utilities that have exposed assets covering large areas [2].

As far as telecommunication system is concerned, lightning surges may propagate in three ways. The first type is called "direct lightning surge" i.e. due to high voltage surges generated by direct lightning discharges striking to the telecommunication cables or devices. Secondly, the voltage induced by electrostatic or electromagnetic coupling from a nearby lightning hit, is called 'induced lightning surge'. Thirdly when lightning strikes the ground, its potential rises and, as a result, ground potential of the appliances may become high. A lot of information has been collected on lightning effects on telecommunication systems during last few decades [3-5].
Lightning usually do not strike on telecommunication cables directly. However, if it does, the result could be melting of the cable and significant damages to the connected devices. Majority of lightning surges appearing on telecommunication cables occur due to indirect coupling [6-8].

Lightning surges can occur quite frequently especially in rainy seasons. Consequently, there have been growing concerns over the damages and disturbances caused by lightning at subscriber equipment, distribution points, cabinet and line cards of Multi-Service Access Nodes (MSAN) of telecommunication networks. Therefore a proper protection system should: (a) provide protection against indirect lightning strikes, (b) provide an effective earth termination network for discharge of lightning current and (c) prevent entering of conducting surges to equipment cabins [9-11].

Miss. B.T. Hemamali, B.Sc.Eng.(Hons), Engineer-Schneider Electric

Miss. D.G.A.R. Lakmali, B.Sc.Eng.(Hons), Engineer-CECB

Miss. H.M.T.M. Kumari,B.Sc.Eng.(Hons), Assistant

Lecturer-SLIIT

Eng. (Prof.) M.A.R.M Fernando, B.Sc.Eng, Tech Lic. PhD,

FIE(Sri Lanka),CEng, Int PE, SMIEEE, Professor

Eng. J.R.S.S. Kumara,B.Sc.Eng,Mphil,Tech Lic.

PhD,MIEEE, AMIE(Sri Lanka),Senior lecturer

Department of Electrical and Electronic Engineering, Faculty of Engineering, University of Peradeniya. 
This study basically addresses three important aspects of lightning on telecommunication systems: the instantaneous voltages created by the travelling wave due to indirect coupling mechanism, the grounding effect of the metallic cable sheath upon the resulting induced surge and the reflection and oscillation phenomena of transient voltage caused by the connecting cables. Finally a case study conducted with the aid of a practically verified simulation model in order to depict so called aspects is also presented.

\section{Telecommunication networks}

The telecommunication system belonging to Sri Lanka Telecom comprises with three main sections, namely: Core, Aggregation and Access Networks. This study focuses only on the access networks of the Public Switched Telephone Network (PSTN). There are two types of telecommunication networks namely (i) Copper wired network, and (ii) Optical fiber access network. The optical fiber access network is categorized into two groups as (i) Fiber To The Node (FTTN) and Fiber To The Home (FTTH), Sri Lanka Telecom presently use copper network, FTTN network and FTTH network.

\subsection{Copper wired network}

The copper wired access network comprises with different components such as main distribution frame (MDF), cabinet, distribution point (DP) and the subscriber end. Figure 1(a) shows a typical architecture of copper access network with all the entry points of the lightning surges into the system. Figure 1(b) shows photographs of each component. Here letters A-H show exchanger, MDF, cable vault, manhole, cabinet, distribution point, discharger, and rosette respectively.

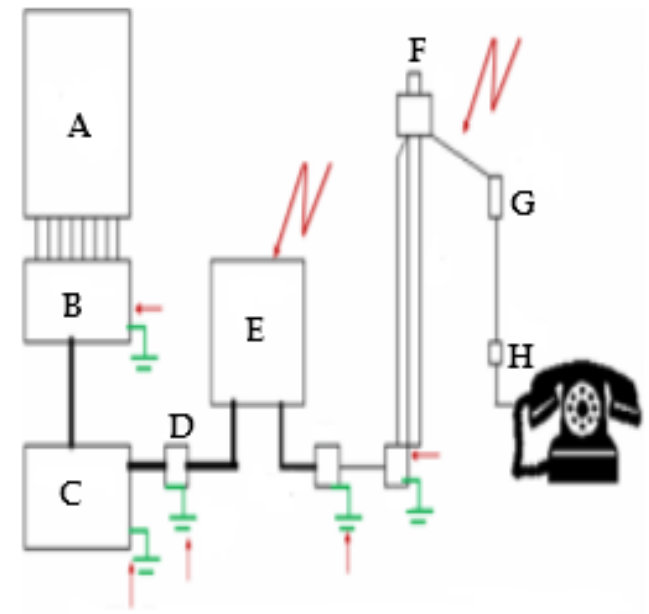

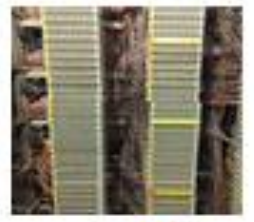

MDF

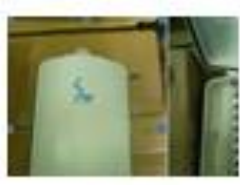

DP

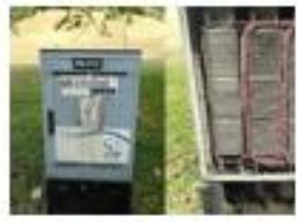

Cabinet

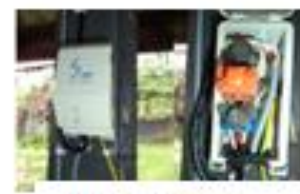

Discharger (b)

Figure 1(a)-Typical arrangement of the copper access network, 1(b) Photographs of each component

Lightning surges can enter the copper network from outdoor cabinet and overhead lines as marked in red color as lightning entry points. Since MDF, cable vault, Man holes, cabinet, DP and discharger have grounding points, surges can exit through them. On the other hand, a significant instantaneous ground potential rise may occur during surge exists. The main components can be described as follows.

\subsubsection{Main distribution frame (MDF)}

MDF is the interface between telephone exchanger and telephone cables consisting of two sides: i.e. line side (UG side) and exchange side. MDF provides protection for the exchange side equipment from over-current and overvoltages that might come from the line side using surge arresters installed in tag blocks at line side.

\subsubsection{Cabinet}

Cabinet connects the primary side (MDF to cabinet) and secondary side (Cabinet to Distribution Point) cables. Sheath of the cables and the steel frame are grounded for lightning protection.

\subsubsection{Distribution Point (DP)}

A ten pair cable is taken from the secondary cable drawn from the cabinet where each pair forms a loop. From the DP, overhead telephone wires are drawn to the subscriber premises. The DP consists of surge arresters as the overvoltage protective devices. The sheath of the incoming cable is grounded for further protection.

(a) 


\subsubsection{Discharger}

Discharger is the protective device installed at the subscriber premises. It consists of surge arrester and grounding arrangement. The discharger protects the telephone from overvoltage surges such as lightning.

\subsubsection{Cables}

Mainly, there are two types of cables used in the distribution network. They are: underground cables and overhead cables. Overhead cables are further categorized as aerial cables and drop wires. In most of the cases underground cables are used from MDF to cabinet whereas either aerial or underground cables are used from cabinet to DP. From DP to discharger, a drop wire is normally used. Underground and aerial cables are usually, bundled together with a cable sheath. Cables of copper network comprise of $0.4 \mathrm{~mm}, 0.5 \mathrm{~mm}$ and $0.65 \mathrm{~mm}$ twisted pair cables.

\subsection{Fiber To The Node Network (FTTN)}

At present Sri Lanka Telecom's communication access network is being converted to an optical fiber based network and the network edge will be extended closer to the subscriber. Main advantages of using optical fiber are less attenuation and high bandwidth. Fiber optic cables are normally composed of totally nonconductive materials. Optical fiber can only respond to light signals in the frequency range of $\mathrm{THz}$ whereas lightning surges' frequency spectrum covers in $\mathrm{MHz}$. This leads to one of the most important advantages of this form of transmission, a fiber optic cable will not be affected by any electromagnetic interference such as lightning.

In optical fiber networks, MSANs are introduced and it extends the network edge closer to the subscriber. MSAN is a device typically installed in a telephone exchange (although sometimes in a roadside serving area interface cabinet) which connects customers' telephone lines to the aggregation network, to provide voice, data and media all from a single platform. MSAN unit consists of line cards, optical fiber cables, MDF, power unit etc. [12]. Gas discharge tube surge arrestors installed in tag blocks and earthing provide protection against over voltages.

Figures 2(a), 2(b) and 2(c) show photographs of surge protective devices, each section of the MSAN box and the earthing system of a MSAN unit respectively.

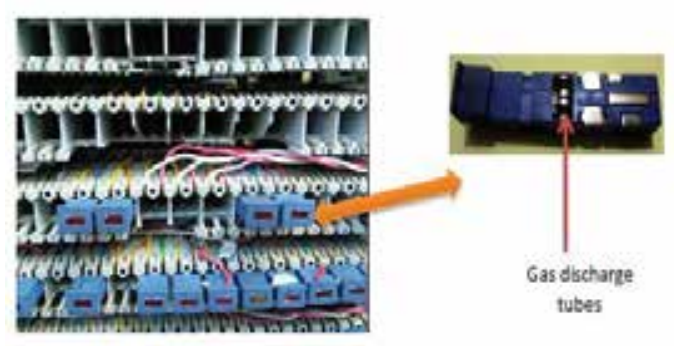

(a)

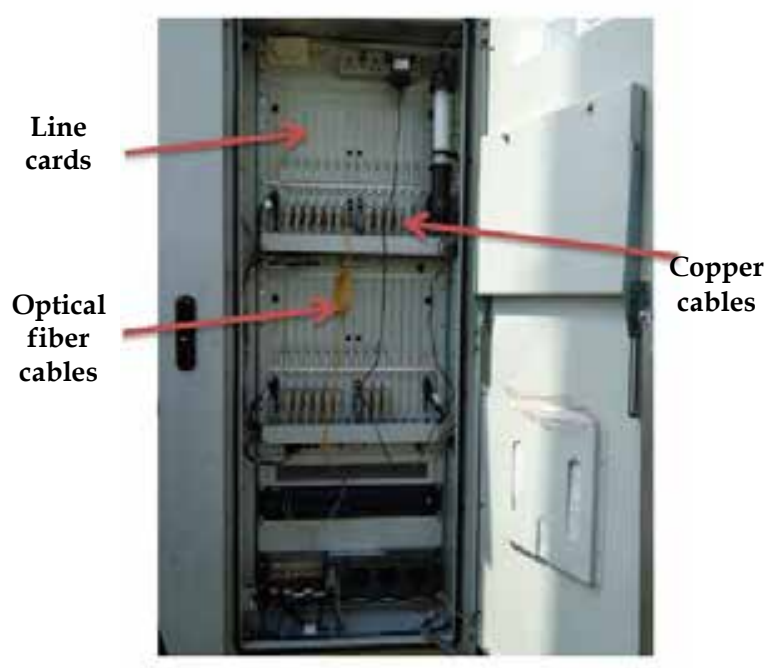

(b)

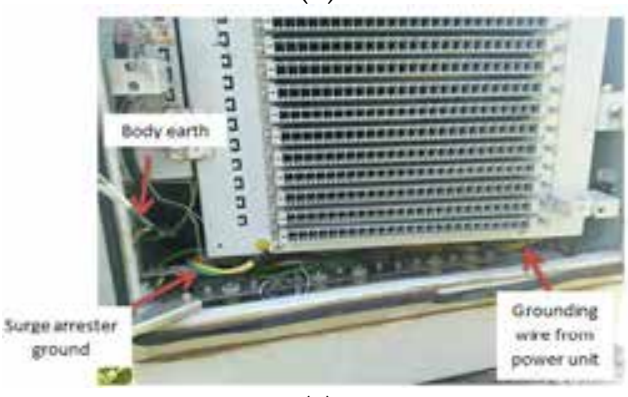

(c)

Figure 2 - (a) MDF tag blocks and surge arrester, (b) Inside the MSAN unit, (c) MDF and earth bar of the MSAN.

\subsection{Fiber to the Home (FTTH)}

Currently Sri Lanka Telecom is expanding the FTTN access network to FTTH which provides multiple-services such as high definition channels on PEO TV, high speed internet access, DATA services, video on demand, Wi$\mathrm{Fi}$, VoIP etc. Fiber to the home (FTTH), also called fiber to the premises (FTTP), is the installation and use of optical fiber from a central point directly to individual buildings such as residences and apartment buildings. Since optical fiber is installed from the central office directly to the subscriber premises, it will not be affected by any electromagnetic interference such as lightning. However, this option is very expensive compared to other two networks. 


\section{Modelling and model verification}

In this study two types of telecommunication networks: namely copper network and FTTN network were considered. As shown in Figure 3 first the individual components were modelled in PSCAD/EMTDC software. Voltages appearing at different points of the components were calculated by simulations and experimentally verified by measurements on individual components. Then models of individual components were combined to simulate the complete copper network and the FTTN network. Then laboratory prototypes of each network type were developed using hardware components which are used in Sri Lanka Telecom. The complete network models were verified by measurements on the prototypes.

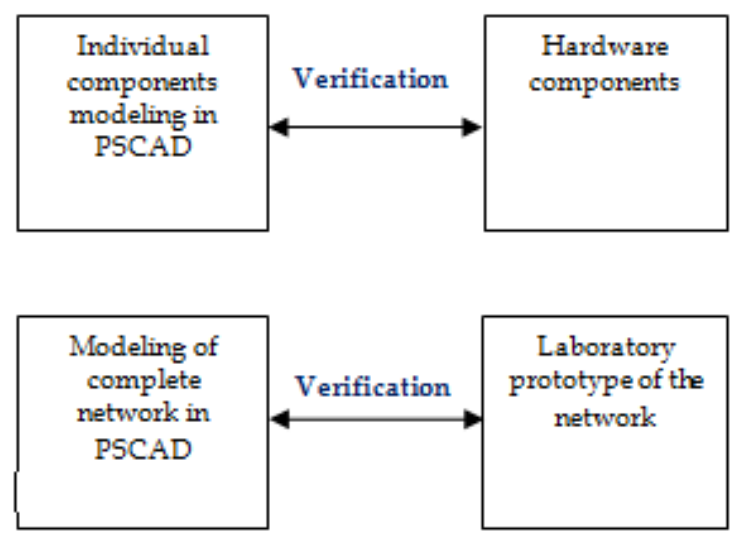

Figure 3- Block diagram for modelling and verification

\subsection{Lightning surge}

A surge corresponding to induced lightning surge specified in IEC 60950-1 was generated from HAEFELY PS1500 surge generator. The same surge waveform was modeled in PSCAD/EMTDC software as a double exponential function:

$$
V(t)=V_{0}\left(e^{-\alpha t}-e^{-\beta t}\right)
$$

Where $\alpha$ and $\beta$ are constants related to rise time and time to half [13], which were $8 \mu$ s and $45 \mu \mathrm{s}$ respectively in this case.

A resistive voltage divider consisting of two resistors having a ratio of 1000:1 (10 $\mathrm{M} \Omega$ and $10 \mathrm{k} \Omega$ ) was used to reduce the output voltage to a low a level so that it can be monitored using an oscilloscope. Test setup used for the experiments is shown in Figure 4.
Laboratory Prototype

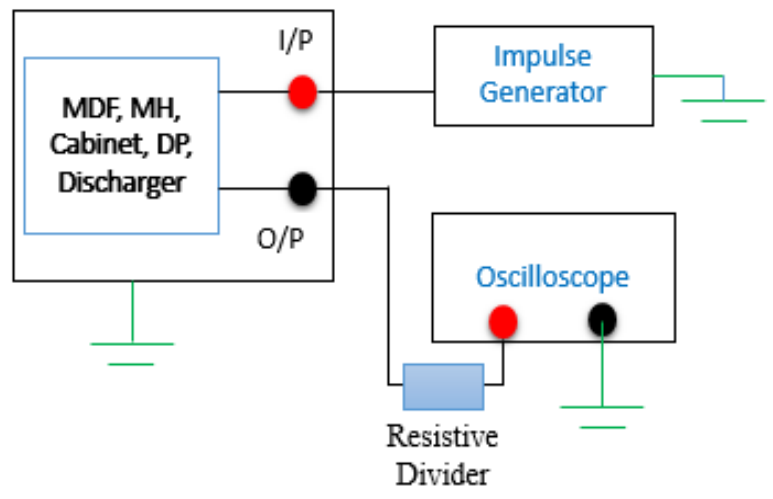

Figure 4- Block diagram of test setup

The comparison of normalized waveforms (modelled and observed) is shown in Figure 5. It is very clear that modelled waveform is identical to the generated waveform.

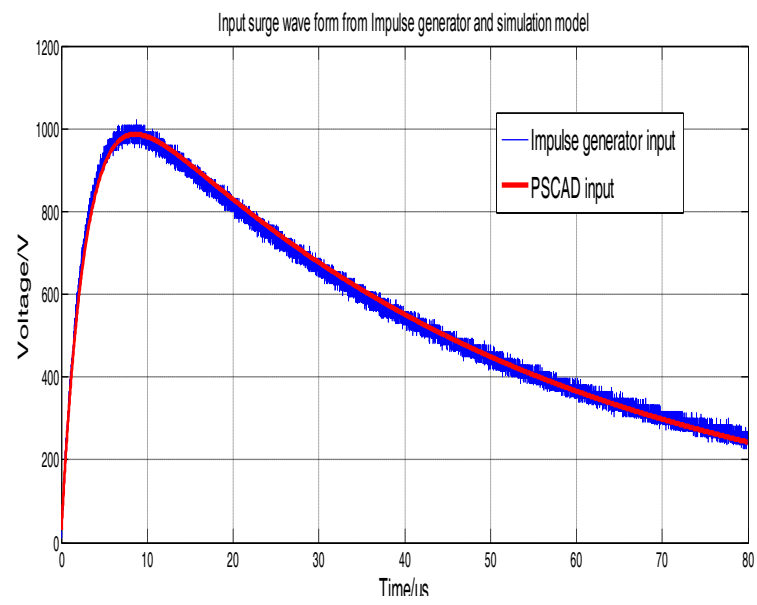

Figure 5-Normalized surge waveforms

\subsection{Copper access network}

First, each individual component (i.e. MDF, Cabinet, Discharger, DP and cables) of the copper network was modelled using PSCAD/EMTDC [14]. Suitable connection points as well as ground points were also included in the model.

The transmission line model was used to model the twisted pair cables. The high frequency model for twisted pair cables consists of series resistors $R$, inductors $L$ and parallel capacitors $\mathrm{C}$ and admittance $\mathrm{G}$ as shown in the Figure 6.

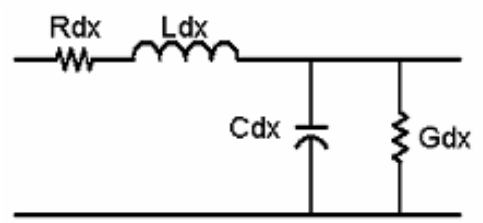

Figure 6- Transmission line model 
The effect of G was neglected and the RLC components of a twisted pair cable were measured at the laboratory and verified with the theoretical values. Table 1 shows the calculated and measured line parameters for $0.4 \mathrm{~mm}, 0.5 \mathrm{~mm}$ and $0.65 \mathrm{~mm}$ cables. The measured and calculated results were in similar range.

Table 1- Measured and calculated values of line parameters

\begin{tabular}{|c|c|c|c|c|c|c|}
\hline \multirow{2}{*}{ Parameter } & \multicolumn{2}{|c|}{$\begin{array}{c}0.4 \mathrm{~mm} \\
\text { Cable }\end{array}$} & \multicolumn{2}{c|}{$\begin{array}{c}0.5 \mathrm{~mm} \\
\text { Cable }\end{array}$} & \multicolumn{2}{c|}{$\begin{array}{c}0.65 \mathrm{~mm} \\
\text { Cable }\end{array}$} \\
\cline { 2 - 7 } & $\mathrm{M}$ & $\mathrm{C}$ & $\mathrm{M}$ & $\mathrm{C}$ & $\mathrm{M}$ & $\mathrm{C}$ \\
\hline $\mathrm{R}[\mathrm{m} \Omega / \mathrm{m}]$ & 145.2 & 134 & 88.3 & 85.6 & 67.7 & 50.6 \\
\hline $\mathrm{L}[\mathrm{nH} / \mathrm{m}]$ & 5.9 & 4.6 & 3.6 & 2.9 & 2.8 & 2.4 \\
\hline $\mathrm{C}_{1}[\mathrm{pF} / \mathrm{m}]$ & 40 & 46 & 50 & 54 & 65 & 69 \\
\hline $\mathrm{C}_{2}[\mathrm{pF} / \mathrm{m}]$ & 56 & 62 & 67 & 73 & 68 & 75 \\
\hline
\end{tabular}

M-Measured values

C-Calculated values

Where, $\mathrm{R}$ is the $\mathrm{dc}$ resistance, $\mathrm{L}$ is the inductance, $C_{1}$ and $C_{2}$ are capacitances between the twisted pair and between the shield and conductor.

After verifying each sub model (MDF, Cabinet, Discharger and DP) laboratory prototype was built-up by combining hardware components of each sub model. Grounding mesh of the high voltage laboratory at Faculty of Engineering, which has an earth resistance of $5 \Omega$ was used as the grounding of the prototype. Simulation model for the laboratory prototype was also developed by combining each sub model accordingly. In the simulation model, a $5 \Omega$ resister was used for grounding.

In order to verify the simulation model, the laboratory prototype was tested by applying $1 \mathrm{kV}$ lightning surge at the MDF. Voltages appearing at different locations were measured and compared with simulation results. Figure 7 shows a photograph of the laboratory prototype of copper access network.

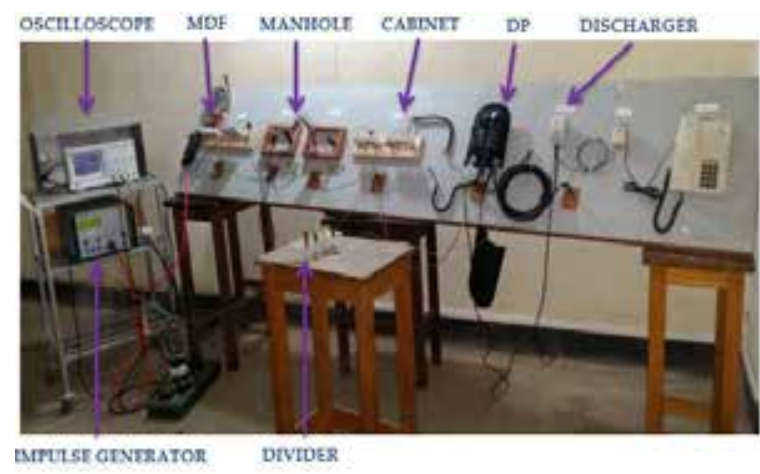

Figure 7-Photograph of the laboratory test setup for copper network

Table 2- Experimental and simulation results for verification of copper network

\begin{tabular}{|c|c|c|}
\hline Location & $\begin{array}{c}\text { From laboratory } \\
\text { test }(\mathrm{V})\end{array}$ & $\begin{array}{c}\text { From } \\
\text { simulation } /(\mathrm{V})\end{array}$ \\
\hline Cabinet & 220 & 215 \\
\hline DP & 208 & 211 \\
\hline $\begin{array}{c}\text { Customer } \\
\text { premises }\end{array}$ & 200 & 203 \\
\hline
\end{tabular}

As shown in the Table 2, experimental and simulation results resonably agree with each other. Slight diferences may be due to not accounting noise, multiple reflections and stray capacitance in the model.

\subsection{Optical fiber access network}

Figure 8 shows the block diagram of optical fiber network. Optical fiber is drawn up to the MSAN unit where as copper cables are used to connect customer to MSAN. Connection between the line card and MDF is also made from copper cables. Similar to the case of copper network, first individual componets namely: MSAN Unit and cable were modelled. In the case of MSAN unit, only the surge arrester and MDF were considered as other components do not have any effect on surge propagation. Surge arrester was simulated by utilizing inbuilt surge arrester model in PSCAD and providing appropiate voltage-current characetrics. Modelling of MDF and cables were same as in the case of copper acsees network.

Since MSANs extend the network edge closer to the subscriber, number of man holes (sheath grounding) and cable length have been reduced. Similar to copper network, laboratory prototype for FTTN network was developed. It consisted of MSAN unit, Man holes, DP, Discharger and telephone. Figure 8(a) shows the block diagram of the FTTN access network 
and $8(\mathrm{~b})$ shows the developed laboratory prototype for the FTTN network.

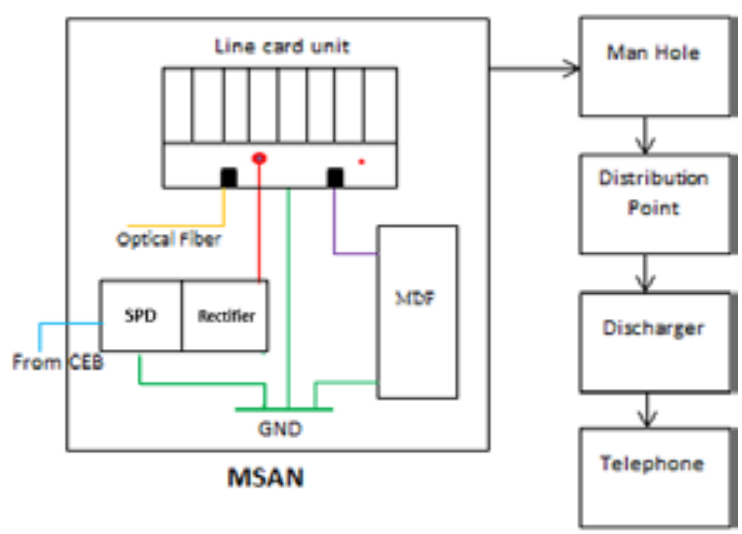

(a)

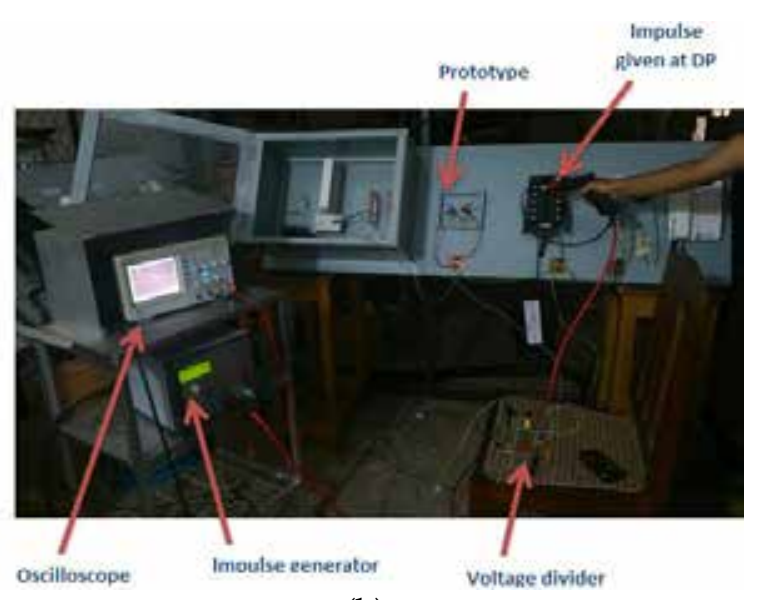

(b)

Figure 8(a)-Block diagram of optical fiber network, 8(b)-Test setup used for FTTN network

Table 3 shows experimental and simulation results of optical fiber network when $1 \mathrm{kV}$ surge is entered from MSAN unit.

Table 3 - Experimental and simulation results for verification of optical fiber network

\begin{tabular}{|c|c|c|}
\hline Location & $\begin{array}{c}\text { From laboratory test } \\
/(\mathrm{V})\end{array}$ & $\begin{array}{c}\text { From } \\
\text { simulation/(V) }\end{array}$ \\
\hline DP & 230 & 220 \\
\hline $\begin{array}{c}\text { Subscriber } \\
\text { premises }\end{array}$ & 225 & 218 \\
\hline
\end{tabular}

Similar to copper access network, simulated results agree with experimental results thus verifying the model performance.

\subsection{Comparison of surge propagation in copper and optical fiber networks}

In order to compare the instantaneous surge voltages appearing at the subscriber premises, a laboratory experiment was conducted by using the developed laboratory prototypes. A lightning surge having peak value of $1 \mathrm{kV}$ was applied at two locations, where practically lightning surges can enter in to the network. The locations are overhead lines (Case A) and MDF or MSAN unit (Case B).

In Table 4 peak voltages as a percentage at the subscriber premises and MDF or MSAN have been compared for two access networks.

Table 4-Experimental results for optical fiber and copper networks

\begin{tabular}{|c|c|c|c|c|}
\hline \multirow{2}{*}{$\begin{array}{c}\text { Peak Value } \\
\text { of the surge } \\
\text { voltage }\end{array}$} & \multicolumn{2}{|c|}{ CASE A } & \multicolumn{2}{c|}{ CASE B } \\
\cline { 2 - 5 } & Copper & $\begin{array}{c}\text { Optical } \\
\text { fiber }\end{array}$ & Copper & $\begin{array}{c}\text { Optical } \\
\text { fiber }\end{array}$ \\
\hline $\begin{array}{c}\text { at customer } \\
\text { premises } \%\end{array}$ & 16.0 & 21.5 & 20.0 & 22.5 \\
\hline $\begin{array}{c}\text { at MDF or } \\
\text { MSAN/\% }\end{array}$ & 24.0 & 28.0 & & \\
\hline
\end{tabular}

When $1 \mathrm{kV}$ surge voltage is applied at the primary side of the MDF or MSAN unit, surge arresters placed at the secondary side were operated as the input voltage was higher than cut off voltage of the arresters $(230 \mathrm{~V})$. This surge waveform was propagated towards the subscriber end and it is about $200 \mathrm{~V}$ for copper network and $225 \mathrm{~V}$ for optical fiber network. Slightly higher voltage in the case of FTTN is due to short cable length and less number of man holes (sheath grounding) of the optical fiber network.

According to the results shown in table 4, in optical fiber network, if the surge enters from the overhead lines, $215 \mathrm{~V}$ of peak voltage will be appeared at the customer premises and $280 \mathrm{~V}$ will be appeared at the MSAN cabin of optical fiber network. If the surge arresters at the MSAN unit have not been properly installed, the line cards of the MSAN unit can be damaged due to that voltage surge. And replacing a line card due to lightning surges will be costly.

The lightning effect will be less significant from the central office to MSAN, since optical fiber cables are drawn between those two locations. But still copper cables are drawn from the MSAN to subscriber premises. Although the copper wires between central office and MSANs are replaced by optical fibers, significant surges can come to the subscriber 
premises and MSAN cabin if the surge enters from overhead lines. Therefore a proper lightning protection mechanism is required at the DP and subscriber premises to ensure the safety at the subscriber premises. However the utility side of the FTTN access network is protected from lightning surges.

\section{Extended studies on copper network}

The outcome of lightning surge entering the PSTN will not only be affected by the RLC components of the PSTN but also vary with the earth resistance characterized by soil resistivity as well as earth electrode configuration. This effect will be even severe due to multiple reflections at terminal loads i.e. mainly the shunt earth resistances. This work was extended by investigating the effect of earth resistance and multiple reflections by means of simulations. For this study, standard lightning impulse (1.2/50 us) voltage was applied.

\subsection{Effect of earth resistance}

4.1.1 Types of earth electrodes used in Sri Lanka Telecom

There are four main grounding points in PSTN: at MDF (central office), cabinet, distribution point and subscriber eustomer premises. GI pipes are used as grounding electrodes for the cabinet and DP whereas copper plated steel rods are used for the discharger at customer premises. Table 5 shows the details of the grounding electrodes used at each of these locations.

Table 5 - Details of earth electrodes used at different locations of the telecom system

\begin{tabular}{|c|cc|}
\hline Location & \multicolumn{2}{|c|}{ Earth electrode details } \\
\hline \multirow{2}{*}{ MDF, } & \multicolumn{2}{|c|}{ GI pipes } \\
Cabinet, & Outer Diameter & $-60 \mathrm{~mm}$ \\
DP & Thickness & $-3 \mathrm{~mm}$ \\
& Length & $-1.5 \mathrm{~m}$ \\
\hline \multirow{2}{*}{ Customer } & Copper plated steel rod \\
Premises & Diameter & $-12 \mathrm{~mm}$ \\
& Length & $-1.2 \mathrm{~m}$ \\
\hline
\end{tabular}

\subsubsection{Modeling of grounding electrodes}

When lightning surge current flow through a ground rod, the grounding system shows transient impedance characteristics depending on the frequency of current flowing into the grounding system. The lightning current gives a wideband frequency spectrum ranging from
DC to a few MHz. The measurement of ground resistance with conventional low frequency measurements might not provide data indicative of the ground response to a lightning surge. Therefore it is necessary to evaluate the high frequency performance of a grounding system for protection against lightning surges [15].

4.1.3 Transmission line model for grounding rod

The distributed parameter circuit model for simulating the frequency-dependent impedance of grounding electrode systems is based on the transmission line theory and is assumed a single layer of soil with uniform resistivity [16]. For this study a single vertical grounding rod was considered. Equivalent circuit for a grounding rod is shown in Figure 9.

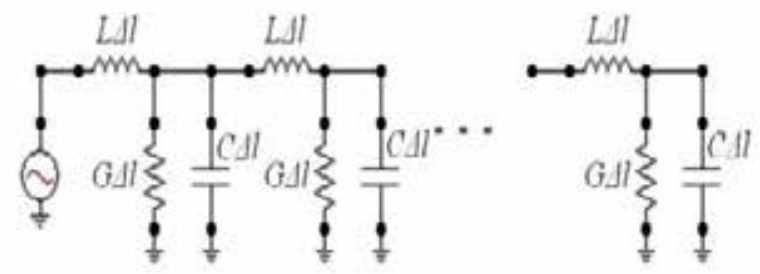

Figure 9 - Equivalent circuits for a grounding rod.

For a vertically buried grounding rod, the ground resistance $\mathrm{R}$ is given by Tagg's equation as follows. [17]

$R=(\rho \ln (4 l / d)) / 2 \Pi l[\Omega]$

Here $1, d$ and $\rho$ represent length of the rod, diameter of the rod and soil resistivity respectively. The leakage conductance G, capacitance $C$ per meter to the ground and inductance, L per meter of the ground rod can be calculated by dividing the lumped parameters by the length of a grounding rod $l$.

$$
\begin{aligned}
& \mathrm{G}=2 \Pi /(\rho \ln (41 / \mathrm{d})[\mathrm{mho} / \mathrm{m}] \\
& \mathrm{C}=2 \Pi \varepsilon_{\mathrm{o}} \varepsilon_{\mathrm{r}} /(\ln (41 / \mathrm{d}))[\mathrm{F} / \mathrm{m}] \\
& \mathrm{L}=\left(\mu_{\mathrm{o}} \ln (41 / \mathrm{d})\right) / 2 \Pi \quad[\mathrm{H} / \mathrm{m}]
\end{aligned}
$$

Three types of soil conditions, which cover the whole range of soil resistivity, were selected in order to perform this simulation. Details of the selected soil are shown in Table 6. 
Table 6 - Properties of the selected soil types [20]

\begin{tabular}{|c|c|c|}
\hline Soil type & $\begin{array}{c}\text { Resistivity } \\
(\rho) /(\Omega \mathrm{m})\end{array}$ & $\begin{array}{c}\text { Relative } \\
\text { permittivity }\left(\varepsilon_{\mathrm{r}}\right)\end{array}$ \\
\hline Clay & 100 & $25-40$ \\
\hline Sandy clay & 150 & $10-30$ \\
\hline Sand & 1000 & $4-6$ \\
\hline
\end{tabular}

Equivalent transmission line models for the grounding rods were developed by calculating the line parameters of L, C and G according to the above parameters. Calculated values of $\mathrm{L}$, $C$ and $G$ for sand, clay and sandy clay are shown in table 7.

Table 7- Parameter values of high frequency ground models for different soil conditions

\begin{tabular}{|c|c|c|c|c|}
\hline \multirow{4}{*}{ Location } & Soil & $\begin{array}{c}\mathrm{G} \\
(\mathrm{S} / \mathrm{m})\end{array}$ & $\begin{array}{c}\mathrm{C} \\
(\mathrm{pF} / \mathrm{m})\end{array}$ & $\begin{array}{c}\mathrm{L} \\
(\mu \mathrm{H} / \mathrm{m})\end{array}$ \\
\hline \multirow{2}{*}{ Discharger } & $\begin{array}{c}\text { Clay } \\
\text { clay }\end{array}$ & 0.01 & 324.8 & 1.2 \\
\cline { 2 - 5 } & sand & 0.00105 & 46.4 & 1.2 \\
\hline \multirow{2}{*}{$\begin{array}{c}\text { MDF, } \\
\text { DP }\end{array}$} & Clay \\
\cline { 2 - 5 } & $\begin{array}{c}\text { Sandy } \\
\text { clay }\end{array}$ & 0.00136 & 422.6 & 0.92 \\
\cline { 2 - 5 } & Sand & 0.00136 & 60.3 & 0.92 \\
\hline
\end{tabular}

\subsection{Effect of multiple reflection}

Objective of this study is to investigate the effect of the multiple reflections in PSTN and see whether it can create a potentially harmful situation to equipment and to the subscriber.

4.2.1 Reflection of lightning surge at a discontinuity point/a Junction/a terminal load

When a travelling wave (the lightning surge), enter a discontinuity point, or a junction or a terminal load, part of the surge may reflect while the other part transfer to the other side. These two components (reflected and transmitted) are determined by the reflection co-efficient and transmission coefficient of the system.

To analyze the multiple reflections, first characteristic impedances of each location of the telecommunication system was calculated and then transmission and reflection coefficients were calculated. The network can be simplified if the network nodes have considerable values for reflection coefficients.
So for other nodes, the incoming wave can be assumed to be completely transmitted.

\subsubsection{Multiple reflections using Bewley's method}

For this analysis Bewley's method, which was modeled using MATLAB software, was used. Consider the distribution point (point A) and the subscriber premises (point B) of a telecommunication network. Let $\mathrm{a}_{1}$ and $\mathrm{a}_{2}$ be transmission coefficients for a wave incident at $A$ and $B$ respectively and $\beta 1$ and $\beta_{2}$ be the corresponding reflection factors when surge enters between DP and discharger.

Characteristic impedances were calculated using the line parameters of the cables. Consider the following line diagram with a distribution point and a discharger. $Z_{4}$ and $Z_{5}$ are earth resistances at DP and discharger together with the characteristic impedance of surge arresters.

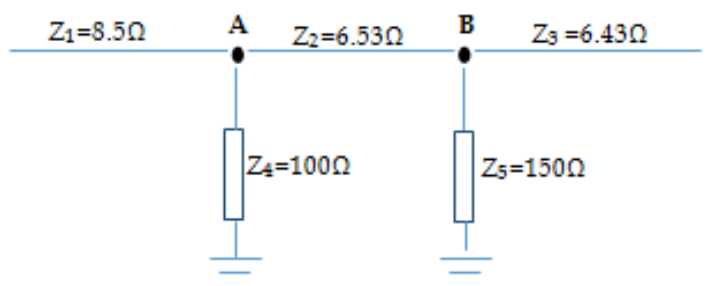

Figure 10 - Line diagram of DP and discharger with characteristic impedances

Transmission coefficients $(\alpha)$ and reflection coefficients $(\beta)$ at a point can be calculated using the equations: (Consider the point $\mathrm{A}$ )

$$
\begin{aligned}
& \alpha=\frac{2 / Z_{1}}{1 / Z_{1}+1 / Z_{2}+1 / Z_{3}} \\
& \beta=\frac{1 / Z 1-1 / Z 2-1 / Z 3}{1 / Z_{1}+1 / Z_{2}+1 / Z_{3}}
\end{aligned}
$$

Transmission and reflection coefficients for the nodes A and B were calculated when the surge entered between points A and B. Calculated values are tabulated as shown in Table 8

\section{Table 8 - Transmission and reflection coefficients system diagram}

\begin{tabular}{|c|c|c|}
\hline Location & $\begin{array}{c}\text { Transmission } \\
\text { coefficient }\end{array}$ & $\begin{array}{c}\text { Reflection } \\
\text { coefficient }\end{array}$ \\
\hline $\begin{array}{c}\text { Distribution } \\
\text { point(A) }\end{array}$ & 1.09 & -0.09 \\
\hline Discharger(B) & 0.971 & -0.03 \\
\hline
\end{tabular}


In the Bewley's lattice diagram, the junctions must be laid off at intervals equal to the time of transit of each section between junctions. (If all lines are overhead lines, then the velocity of propagation may be assumed to be the same and the junctions can be laid off proportional to the distance between them) $[18,19]$

Table 9 shows the relationship between voltage and time at DP and customer.

Table 9 - Relationship between voltage and time for points $A$ and $B$.

\begin{tabular}{|c|c|c|}
\hline \multirow{2}{*}{ Time } & \multicolumn{2}{|c|}{ Voltage } \\
\cline { 2 - 3 } & At DP $(\mathrm{A})$ & At customer(B) \\
\hline $\mathrm{t}_{0}$ & $\mathrm{Va}_{1}$ & $\mathrm{Va}_{2}$ \\
\hline $2 \mathrm{t}_{0}$ & $\mathrm{Va}_{1} \beta_{2}$ & $\mathrm{Va}_{2} \beta_{1}$ \\
\hline $3 \mathrm{t}_{0}$ & $\mathrm{Va}_{1}\left(\beta_{1} \beta_{2}\right)$ & $\mathrm{Va}_{2}\left(\beta_{1} \beta_{2}\right)$ \\
\hline $5 \mathrm{t}_{0}$ & $\operatorname{Va}_{1} \beta_{2}\left(\beta_{1} \beta_{2}\right)$ & $\mathrm{Va}_{2} \beta_{1}\left(\beta_{1} \beta_{2}\right)$ \\
\hline $7 \mathrm{t}_{0}$ & $\operatorname{Va}_{1}\left(\beta_{1} \beta_{2}\right)^{2}$ & $\mathrm{Va}_{2}\left(\beta_{1} \beta_{2}\right)^{2}$ \\
\hline $9 \mathrm{t}_{0}$ & $\operatorname{Va}_{1} \beta_{2}\left(\beta_{1} \beta_{2}\right)^{2}$ & $\operatorname{Va}_{2} \beta_{1}\left(\beta_{1} \beta_{2}\right)^{2}$ \\
\hline $11 \mathrm{t}_{0}$ & $\operatorname{Va}_{1}\left(\beta_{1} \beta_{2}\right)^{3}$ & $\operatorname{Va}_{2}\left(\beta_{1} \beta_{2}\right)^{3}$ \\
\hline $13 \mathrm{t}_{0}$ & $\operatorname{Va}_{1} \beta_{2}\left(\beta_{1} \beta_{2}\right)^{3}$ & $\operatorname{Va}_{2} \beta_{1}\left(\beta_{1} \beta_{2}\right)^{3}$ \\
\hline
\end{tabular}

Where $t_{0}=\mathrm{L} / 2 \mathrm{~V}, \mathrm{~L}$ is distance between $\mathrm{A}$ and $\mathrm{B}$, and $\mathrm{V}$ is the velocity of surge propagation.

Voltage appearing at distribution point and discharger due to $1 \mathrm{kV}$ lightning surge enters between DP and discharger is shown in Table 10 .

Table 10 - Surge voltages at customer and DP due to multiple reflections

\begin{tabular}{|c|c|c|}
\hline \multirow{2}{*}{ Time } & \multicolumn{2}{|c|}{ Voltage/V } \\
\cline { 2 - 3 } & At DP (A) & At customer(B) \\
\hline $\mathrm{t}_{0}$ & 898 & 800 \\
\hline $2 \mathrm{t}_{0}$ & 1057 & 942 \\
\hline $3 \mathrm{t}_{0}$ & 1100 & 885 \\
\hline $5 \mathrm{t}_{0}$ & 1095 & 864 \\
\hline $7 \mathrm{t}_{0}$ & 1078 & 847 \\
\hline $9 \mathrm{t}_{0}$ & 1062 & 834 \\
\hline
\end{tabular}

Waveforms of surge voltage at point $\mathrm{A}$ and point B can be obtained using the Bewley's method which was modeled in MATLAB.

\section{Case Study}

\subsection{Site details}

5.1.1 Location

In order to analyse the effect of lightning on the real system of Sri Lanka Telecom, a route was selected inside the university premises. The route starts from the exchanger at Galaha Junction and terminates at the customer premises closer to the Wijewardana Hall at University of Peradeniya. The selected route is shown in Figure 11.

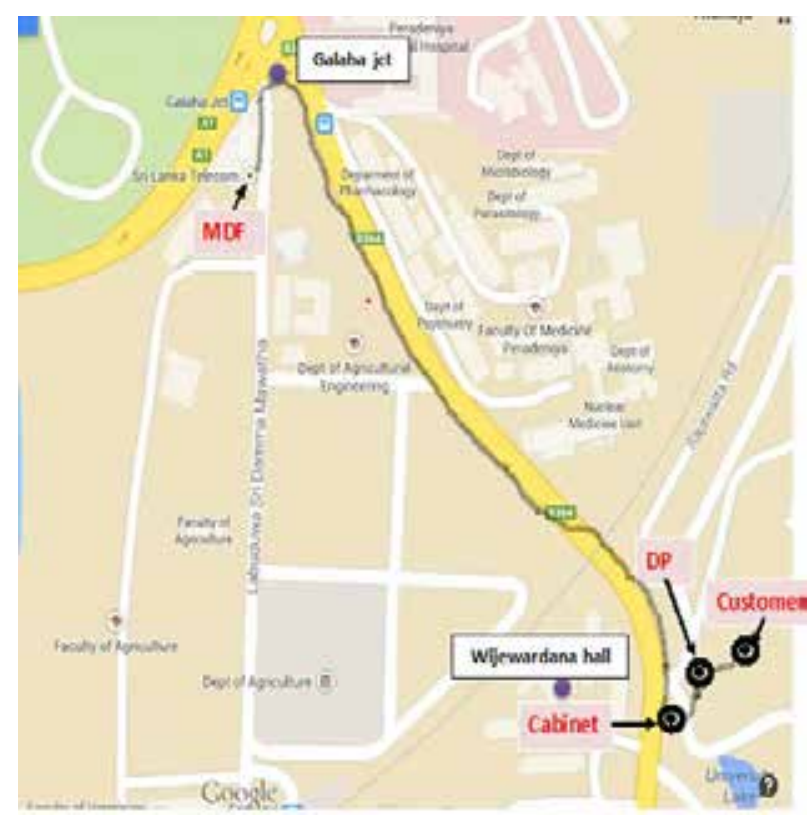

Figure 11-Map of the selected route

\subsubsection{Earth resistances}

As earth resistances at each location of the selected route were essential when modeling the network in PSCAD, a field investigation was carried out to measure the earth resistances of the network. At MDF earth resistance could not be measured due to inaccessibility. In this case a recently measured value from the central office was used. Earth resistance values of the selected network are given in the Table 11. 
Table 11 - Measured and standard earth resistance

\begin{tabular}{|c|c|c|c|}
\hline Location & $\begin{array}{c}\text { Earth } \\
\text { resistance } \\
{[\Omega]}\end{array}$ & $\begin{array}{c}\text { Maximum } \\
\text { allowable } \\
\text { resistance } \\
{[\Omega]}\end{array}$ & Remarks \\
\hline MDF & $\mathbf{4}$ & 2 & $\begin{array}{c}\text { SA and cable } \\
\text { sheath were } \\
\text { grounded }\end{array}$ \\
\hline Cabinet & $\mathbf{1 1 0}$ & 50 & $\begin{array}{c}\text { Sheath and } \\
\text { metal box were } \\
\text { grounded }\end{array}$ \\
\hline DP & $\mathbf{N o}$ & 50 & $\begin{array}{c}\text { No grounding } \\
\text { at DP }\end{array}$ \\
\hline $\begin{array}{c}\text { At } \\
\text { subscriber }\end{array}$ & $\mathbf{1 3 3}$ & 100 & $\begin{array}{c}\text { Surge arrester } \\
\text { was grounded }\end{array}$ \\
\hline
\end{tabular}

\subsubsection{Cable lengths}

Figure 12 shows the single line diagram of the selected route inside the university premises.

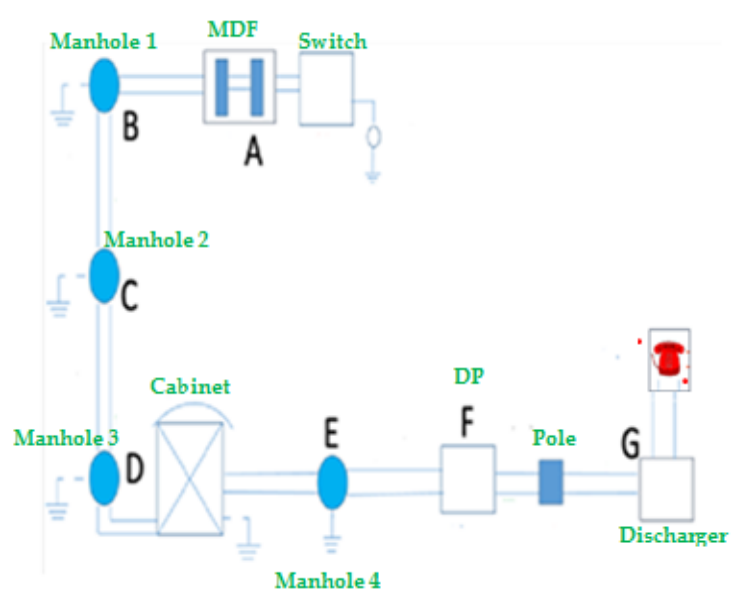

Figure 12 - Single line diagram of the selected route

Here letters A-G show the nodes of the selected route. This selected telecommunication network consists of three types of cables having different diameters: $0.4 \mathrm{~mm}, 0.5 \mathrm{~mm}$ and $0.65 \mathrm{~mm}$. Line lengths between each node are shown in Table 12.

Table 12 - Cable lengths of selected route

\begin{tabular}{|c|c|c|}
\hline $\begin{array}{c}\text { Name of } \\
\text { the line }\end{array}$ & $\begin{array}{c}\text { Cable } \\
\text { diameter/mm }\end{array}$ & Length/m \\
\hline A-B & 0.4 & 61 \\
\hline B-C & 0.4 & 365 \\
\hline C-D & 0.4 & 360 \\
\hline D-E & 0.5 & 180 \\
\hline E-F & 0.5 & 20 \\
\hline F-G & 0.65 & 16 \\
\hline
\end{tabular}

\subsubsection{Transmission and reflection coefficients}

Transmission and reflection coefficients of each node of the selected telecommunication network can be calculated using transmission line parameters and earth resistances. Calculated values are shown in table 13.

\subsection{Simulation study}

The real network described in section 5.1 was simulated using PSCAD. Different studies were carried out to analyze the performance of the existing surge protection during lightning surges. And instantaneous surge voltages at each location were compared with standard surge protection and existing surge protection.

\section{Table 13 -Transmission coefficient and} Reflection coefficient at each node

\begin{tabular}{|c|c|c|c|}
\hline Node & Description & $\begin{array}{c}\text { Transmission } \\
\text { Coefficients }\end{array}$ & $\begin{array}{c}\text { Reflection } \\
\text { Coefficients }\end{array}$ \\
\hline A & MDF & 0.895 & -0.105 \\
\hline B & Man hole 1 & 0.891 & -0.109 \\
\hline C & Man hole 2 & 0.891 & -0.109 \\
\hline D & Cabinet & 0.750 & -0.250 \\
\hline E & Man hole 4 & 0.935 & -0.065 \\
\hline F & DP & 1.09 & -0.09 \\
\hline G & Discharger & 0.971 & -0.03 \\
\hline
\end{tabular}

5.2.1 Instantaneous voltage surges at different locations of the route

A simulation was performed to investigate how much voltage would appear at several critical locations of the selected route due to propagation of induced lightning surges. Most frequently, lightning surges enter to the system through overhead cables via induction. Surge voltages were applied separately at two locations, namely at MDF and in between the DP and the discharger. Then for each location the voltage waveforms appearing at four other locations i.e. (1) the subscriber end equipment, (2) main distribution frame, (3) cabinet and (4) DP, were observed. Obtained results are tabulated in Tables $14 \& 15$ as percentage with respect to input voltage.

A surge with peak voltage of 1 pu was applied at the MDF and the overhead line. Simulations were carried out for three cases: (a) with existing earth resistance and without SPDs, (b) with existing earth resistance and with existing SPDs and (c) with standard earth resistance and with existing SPDs. The simulation results for 
above three cases are tabulated in Tables 14 and 15.

Table 14 -Voltages at different locations of the system when surge enters the line at MDF

\begin{tabular}{|c|c|c|c|}
\hline \multirow{2}{*}{ Location } & \multicolumn{3}{|c|}{ Peak Voltage / (\%) } \\
\cline { 2 - 4 } MDF & Case a & Case b & Case c \\
\hline Cabinet & 98.9 & 23.4 & 23.3 \\
\hline DP & 76.4 & 12.1 & 6.7 \\
\hline Telephone & 76.1 & 10.5 & 4.1 \\
\hline
\end{tabular}

Table 15 -Voltages at different locations when surge enters the line from overhead line

\begin{tabular}{|c|c|c|c|}
\hline \multirow{2}{*}{ Location } & \multicolumn{3}{|c|}{ Peak Voltage / (\%) } \\
\cline { 2 - 4 } & Case a & Case b & Case c \\
\hline MDF & 91.8 & 23.4 & 12.0 \\
\hline Cabinet & 94.4 & 85.8 & 21.6 \\
\hline DP & 96.6 & 99.6 & 23.2 \\
\hline Telephone & 94.4 & 23.3 & 21.9 \\
\hline
\end{tabular}

It can be clearly seen from the Table 14 that without surge arresters a significant amount (i.e. $76 \%$ ) of the surge voltage could be transferred to the customer equipment. If the surge arresters of the selected route functioned well then this voltage would be always less than the cut-off voltage of the surge arresters, in this case it is about $100 \mathrm{~V}$. If both surge arresters functioned well and earth resistances were also within the acceptable limits then the voltage appearing at the subscriber end could be reduced further.

When a surge is applied in overhead lines similar variation could be observed. As far as the voltage wave forms at the MDF are concerned peak values were higher than $230 \mathrm{~V}$ which define the cutoff of the surge arresters. Consequently, the SPDs installed at the secondary side of the exchange would be operated ensuring the protection.

\subsubsection{Effect of earth resistance}

As discussed in section 4.1 the effect of earth resistances was analyzed for this real telecommunication system. In this study grounding resister used in earlier cases was replaced with the developed grounding model. Simulations were performed for three soil conditions cases: (a) Clay (b) Sandy clay and (c) Sand.
Figure 13 shows instantaneous voltage waveforms at the subscriber premises for different soil conditions.

Waveforms with similar shapes were obtained at cabinet and DP. In order to analyze the results obtained from the simulation, the instantaneous peak voltage appeared at each location of the copper network for different soil conditions were tabulated when $1 \mathrm{pu}$ of lightning surge enters to the system. Results are shown in table 16.

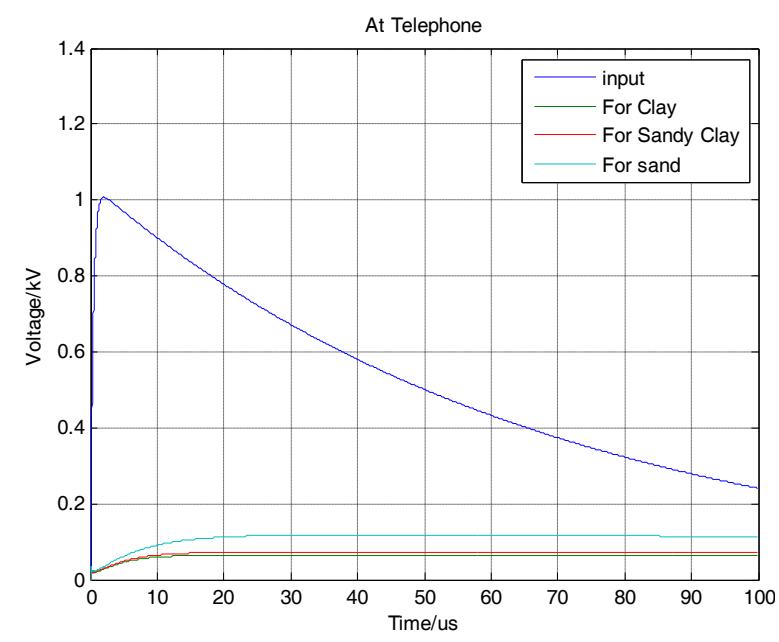

Figure 13 -Voltage appearing at Subscriber premises

Table 16 - Instantaneous peak voltage at different locations of the route

\begin{tabular}{|c|c|c|c|}
\hline \multirow{2}{*}{ Location } & \multicolumn{3}{|c|}{ Peak voltage (pu) } \\
\cline { 2 - 4 } & Clay & $\begin{array}{c}\text { Sandy } \\
\text { clay }\end{array}$ & Clay \\
\hline Cabinet & 0.089 & 0.095 & 0.134 \\
\hline DP & 0.067 & 0.075 & 0.120 \\
\hline Telephone & 0.065 & 0.072 & 0.118 \\
\hline
\end{tabular}

When 1pu surge enters the telecommunication network at MDF peak surge voltage has been attenuated to a value of $0.065 \mathrm{pu}$ at subscriber premises for clay type soil. For sandy clay it is about $0.072 \mathrm{pu}$ and for sand it is $0.118 \mathrm{pu}$. Therefore it is clear that when soil condition changes from clay to sand resultant frequency dependent impedance of the ground rod has been increased. As a result, voltage appearing at the subscriber end has increased for sand type soil. Therefore in such areas grounding 
performance can be enhanced by other means like treating soil or using parallel electrodes. Thus voltage appearing at subscriber end can bring to a somewhat lesser value than above.

\subsubsection{Effect of multiple reflections}

The telecommunication system described in section 5.1 was modeled in MATLAB, to analyze the effect of multiple reflections of selected access networks. Bewley's method was used to obtain the surge waveform appeared at subscriber premises when the surge is entered between the distribution pole and the discharger. Effect of multiple reflections was analyzed for the worst case which can be happened in the copper wired access network. Surge waveforms at DP and discharger are shown in Figures 14(a) and 14(b).

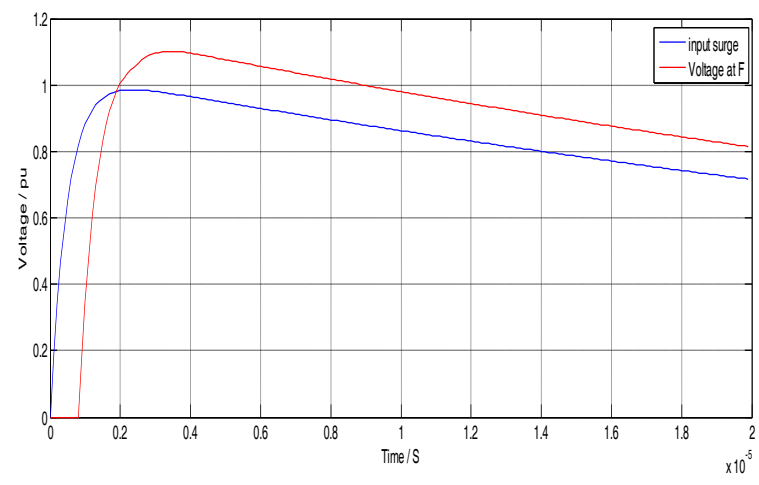

(a)

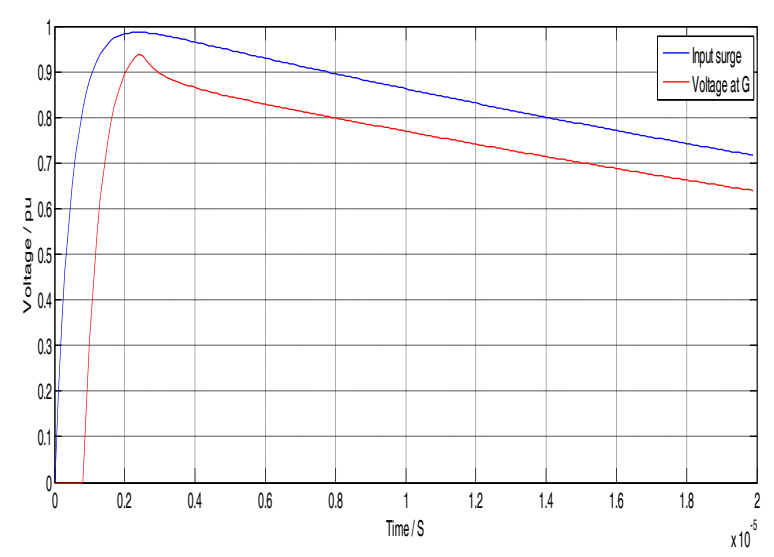

(b)

Figure 14 (a)-Voltage at DP (point F) for small period of time, 14(c)-Voltage at discharger (point G) for small period of time

When 1 pu of lightning surge enters between DP and discharger, the surge voltage appered at subscriber end has reduced to $0.940 \mathrm{pu}$ and peakvalue of surge voltage appeared at DP has increased to $1.100 \mathrm{pu}$ due to the effect of multiple reflections. Therefore this transmitted signal with higher surge voltage at DP due to the effect of multiple reflections can create a potentially harmful situation to the telecommunication system.

\section{Conclusions}

The characteristics of induced lightning surges in existing access networks of Sri Lanka Telecom vary according to the RLC components of the PSTN, earth resistance characterized by soil resistivity and earth electrode configuration and the multiple reflections characterized by cable lengths and surge impedances of the PSTN components. Induced voltage due to lightning would be at a lower level if the telecommunication network has proper surge protection. Instantaneous surge voltage at the subscriber side can be further reduced when the length of the line and number of sheath grounding increase. Results obtained from the laboratory experiments show that the effect of lightning is less significant in copper access network than the FTTN network. Moreover the voltage appearing at the subscriber end can be changed due to the soil condition. Therefore in such areas voltage appearing at subscriber end can bring to an acceptable value by treating soil or using parallel electrodes. It was found that the potentially harmful situations can be occurred in telecommunication systems due to the effect of multiple reflections.

In particular, the results obtained from the field investigation carried out inside the university premises show that the lightning surge can be completely transferred to the subscriber unless proper protective measures are taken. This analysis gives quantitative measurements of the voltages appearing at the end user for different cases discussed above.

\section{Acknowledgement}

The authors would like to express their gratitude to University of Peradeniya providing resources to complete this project. Special thank goes to Sri Lanka Telecom for providing equipment and for giving their valuable time in sharing their knowledge throughout the gathering of information relevant to this project. Finally, we offer our regards and blessing to all those who supported in any respect during the completion of the project. 


\section{References}

1. Kuffel, E., Zaengl, W. S. and Kuffel, J., "High Voltage Engineering Fundamentals", 2nd ed., UK, Butterworth Heinemann, 2000, pp. 48-60.

2. Gohara, E.,"A practical approach of lightning protection measures for power receiving facilities in telecom building", Telecommunications energy conference, IEEE $36^{\text {th }}$ international,Oct 2014,pp. 1-5.

3. Bennison, E., "Lightning Surges in Open Wire, Coaxial and Paired Cables", IEEE Transactions on Communications, Vol. 21, No. 10, Oct 1973

4. Tominaga, T., "Characteristics of Lightning Surges Induced in Telecommunication Centre in Tropical Area ", IEEE transactions on Electromagnetic compatibility, Vol. 45, No. 1, Feb 2003

5. Bodle, D. W. and Gresh, P. A., "Lightning Surges in Paired Telephone Cable Facilities", Bell system technical journal, Vol. 40, No. 2, March 1961

6. Rakov, V. and Uman, M., "Lightning - Physics and Effects", New York: Cambridge University Press, pp. 214-234, 2003

7. Randolph, J., " Introduction to lightning and AC power fault surges protection for telecom signalling cables", IEEE Symposium on Product Compliance Engineering (ISPCE),pp. 1-11, Nov 2012

8. Ahmad, A. S., and Aka-Ngnui T., "Lightning induced voltage on telephone cables and power systems", International Conference on Power Systems Transients (IPST'07) in Lyon, France on June 4-7, 2007

9. Ikeda, G., “Lightning conditions in Ceylon, and measures to reduce damage to electrical equipment", Asian Productivity organization report, May 1969

10. Lock, K., "Lightning Protection, Earthing and Surge Protection of Base Transmission Stations", Lightning (APL) 7th Asia-Pacific International Conference of IEEE, Chengdu, Singapore, Nov 2011, pp. $436-440$

11. Kitano, H., Sakai, K., Sato, H., Matsumura, H., Murao, T., and Suzuki, H., “Design Technology for an External Lightning Protection System for a Telecommunications Building", NTT Technical Journal, Vol. 5, No. 12, Dec 2007

12. Brett Handley, "Multi-Service Access Nodes (MSANs): Gateways to Next-Generation Network (NGN)", FUJITSU Sci. Technical journals, 42.4, Oct 2006, pp. 432-438
13. Kamarudin, M. S., Sulaiman, E., Ahmad M. Z., Impulse Generator and Lightning Characteristics Simulation", Proceedings ofEnCon2008, 2nd Engineering Conference on Sustainable Engineering Infrastructures Development\& Management, SarawakMalaysia, Dec 2008

14. User manual, "PSCAD power systems computer aided design", Manitoba-HVDC research centre, Canada, online Available: http://www.ien.pw.edu.pl/install/PSCAD/PS CAD\%204.2.1_Professional\%20+\%20LiveWire\% 202.3_zakup\%20z\%20grantu2008/Install/PSCA DV4/Help/HelpManuals/PSCAD\%20Users\%20 Guide.pdf

15. Grcev, L., "Modeling of grounding systems for better protection of communication installations against effect from electrical power system and lightning", Browse conference publications, Telecommunication energy conference, twentythird international, Oct 2001, pp. 461-468.

16. Grcev, L., "Modeling of grounding electrodes under lightning currents", IEEE Trans. on Electromagnetic Compatibility, Vol. 51, pp. 559571, Aug 2009

17. Lee, B. H., Joe, J. H. and Choi, J. H., "Simulation of Frequency-dependent impedance of grounding rods considering multi-layered soil structure", Journal of Electrical Engineering \& Technology, Vol. 4, No.4, 2009, pp.531-537.

18. Aodsup, K. and Kulworawanichpong, T., "Simulation of Lightning Surge Propagation in Transmission Lines Using the FDTD Method", World Academy of Science, Engineering and Technology, issue 71, Nov 2012

19. Liu, y., Tong, L.,. Zhu W. X., Tian Y. and Gao, B., "Impedance measurements of non-uniform transmission lines in time domain using an improved recursive multiple reflection computation method", Progress In Electromagnetic Research, Vol. 117, 2011, pp.149-164.

20. Alex, M., Alan, P. Byrnes, "Modelling Dielectricconstant values of Geologic Materials: An Aid to Ground-Penetrating Radar Data Collection and Interpretation", Kansas Geological Survey,Lawrence,2001 